University of Massachusetts Amherst ScholarWorks@UMass Amherst

Resource Economics Department Faculty

Publication Series

Resource Economics

1999

\title{
Attitudes and preferences toward co-operative agreements for management of private forestlands in the North-eastern United States
}

\author{
TH Stevens \\ D Dennis \\ D Kittredge \\ M Rickenbach
}

Follow this and additional works at: https://scholarworks.umass.edu/resec_faculty_pubs

\section{Recommended Citation}

Stevens, TH; Dennis, D; Kittredge, D; and Rickenbach, M, "Attitudes and preferences toward co-operative agreements for management of private forestlands in the North-eastern United States" (1999). Journal of Environmental Management. 159.

Retrieved from https://scholarworks.umass.edu/resec_faculty_pubs/159 


\title{
Attitudes and preferences toward co-operative agreements for management of private forestlands in the North-eastern United States
}

\author{
T. H. Stevens*†, D. Dennisł, D. Kittredgeף and \\ M. Rickenbach§
}

Forest fragmentation is increasing throughout much of the United States. Co-operative management agreements are a potential solution to this problem and this case study suggests that non-industrial private landowners in the North-eastern United States are as likely to undertake collaborative management programs as they are to undertake the same management programs independently. However, the probability of undertaking any of the management programs examined in this study was low, suggesting that incentives for co-operative management between landowners may be needed. And, regardless of whether management is co-operative or independent, the estimated probability of program adoption is higher when management focuses on amenities, such as wildlife habitat, compared to timber harvests.

(C) 1999 Academic Press

\section{Introduction}

Nearly three-quarters of the forest land in the United States (USDA Forest Service, 1988) and just over half of the forest land in Europe (Kuusela, 1994) is privately owned. Moreover, political changes in the formerly communist countries of central and eastern Europe have resulted in massive privatisation of forestland (Marghescu, 1997). These privately owned forests are expected to play an important role in meeting future needs for timber, recreation, wildlife habitat, biodiversity and other forest related goods and services (USDA Forest Service, 1995; Kuusela, 1994). Unfortunately, increasing fragmentation of these lands can adversely affect many important forest related values or benefits, particularly those that transcend legal boundaries (e.g. water quality, wildlife habitats, biodiversity and some recreational opportunities).

Co-operative management agreements wherein individual landowners collaborate to manage their forest land as part of a larger unit is one potential solution to some of the problems associated with fragmentation.
However, private landowners have little financial incentive to participate in co-operative management because non-timber outputs are generally non-exclusive and have little or no market value. Moreover, since little is known about non-industrial private forest (NIPF) landowners' attitudes and preferences toward co-operation with others to achieve management objectives, public programs which effectively promote co-operation have generally not been developed (Rickenbach et al., 1998).

Fragmentation is of particular concern in the North-eastern United States where almost three-quarters of the forest is NIPF. More than half (55\%) of the forest land held by individuals in the North-east is in parcels that are less than 100 acres or approximately 40.5 hectares (Birch, 1996). In regions such as this, landowner co-operation is a key component in accomplishing many management objectives.

In this study, conjoint analysis was used to elicit landowner attitudes and preferences about co-operative management agreements involving both timber and non-timber objectives. A brief discussion of previous research, and the conjoint technique is followed
†226 Draper Hall, University of Massachusetts, Amherst MA 01003, USA $\ddagger U S D A$ Forest Service, Northeastern Forest Experiment Station, PO Box 968, 705 Spear Street, Burlington, VT 95492, USA I Holdsworth Hall, University of Massachusetts, Amherst MA 01003, USA §Forestry Extension, 119 Peavy Hall, Oregon State University, Corvallis, OR 97330, USA

* Corresponding author

Received 29 October 1997; accepted 27 July 1998

This research was supported by funds provided by the US Department of Agriculture, Forest Service, Northeastern Forest Experiment Station. 
by a case study of forest landowners in Massachusetts, USA.

\section{Background and methods}

In one of the few empirical studies on this topic, Brunson et al. (1996) surveyed NIPF owners about attitudes toward collaborative management in three US regions: the Southeast, Midwest and Interior West. When asked to respond to the statement that "public and private landowners should plan activities jointly because ecosystems and wildlife cross property boundaries', about $80 \%$ of all respondents rated this concept as 'appropriate' or 'highly appropriate' for public lands. But, only $23 \%$ of Utah and South-east respondents and $14 \%$ of Midwest (Indiana) respondents said they would definitely be willing to plan activities jointly if their own land was involved. Most wanted to see a demonstration project before deciding whether to participate. Brunson et al. (1996, p.20) conclude that

'many NIPF owners are deeply concerned about property rights, and this may make them less supportive of ecosystem management strategies that call for power-sharing among groups of landowners. However, wariness about property rights may be offset by NIPF owners' deeply rooted beliefs about forest stewardships and the need to protect natural environment.'

More recently, Rickenbach et al. (1998) surveyed 1250 NIPF landowners in Massachusetts. Most respondents believed that their actions affect land elsewhere and were favorably disposed to the idea of working with others. However, Rickenbach et al. (1998, p.21) note that the degree to which respondents considered how such (co-operative) arrangements might work, the extent of participation, and the costs involved were not addressed in the context of this survey.

We also used survey approach to examine landowner attitudes about collaborative management efforts. Our survey employed a conjoint technique to elicit information about the likelihood that individuals would participate in management programs involving co-oper- ation. Forest landowners were asked to rate alternative management scenarios, each of which consisted of a bundle of attributes or management activities, including cost. Landowners were partitioned into two groups. Each received an identical questionnaire except that one group was asked about cooperative management options for a hypothetical set of adjacent privately owned parcels while the other was asked about the same options for a single equivalent parcel owned by the individual. Relevant portions of both surveys are present in the Appendix.

As shown in the Appendix, both groups were asked to rate four different management scenarios on a scale of 1-10 with 10 indicating scenarios, if any, the individual would definitely undertake, 1 for scenarios the respondent would definitely not undertake, and if not sure, a rating of 2-9 indicated the likelihood that a scenario might be adopted.

Two conjoint models were estimated. The first was a traditional specification that can be illustrated by assuming alternative forest management programs, consisting of several attributes or activities. Landowner ratings for each program are assumed to be proxies for individual utility. Program ratings were then regressed against program attributes such that:

$$
r^{1}=k+b_{i} q_{i}{ }^{i}+\ldots b_{k} q_{k}{ }^{i}+b_{p} p^{i}
$$

where $r^{i}$ is the ith program's rating, $q_{j}^{i}$ is the program's $j$ th attribute, $p^{i}$ is price or management cost and the $b$ 's are estimated weights associated with each attribute (see McKenzie, 1990, 1993; Boxall et al., 1996; Roe et al., 1996).

As noted by Roe et al. (1996), this traditional formulation does not provide an estimate of the welfare gain or loss of nonmarginal changes, such as moving from one management program to another. Moreover, since many individuals may be uncertain about whether they would actually undertake the programs being considered, results derived from this traditional approach can be misleading.

The second approach taken in this study differs in that only those individuals who said they would definitely undertake each management scenario were counted as participating. It is assumed that each in- 
dividual's decision to participate depends upon program attributes such as extent of timber harvested, management cost, attitudes toward management and individual socio-economic characteristics including age, education and income. The postulated empirical relationship is a binary logit model:

$$
E(Y)=\frac{1}{1+\mathrm{e}^{-\alpha-\beta x}}
$$

where $Y$ is a binary variable such that $Y$ equals 1 for programs that would definitely be undertaken by an individual (conjoint rating $=10$ ) and $Y$ equals 0 otherwise (conjoint rating $=1-9$ ), $x$ is a vector of the explanatory variables outlined above and $\alpha$ and $\beta$ are estimated coefficients. Equation (2) can then be used to calculate the probability, $E(Y=1)$ that a management program consisting of the attributes included in $x$ will actually be adopted.

The survey used in this study asked individuals to rate four management scenarios consisting of one timber and four non-timber attributes: extent of timber harvest, establishment or a recreational trail system, maintenance of apple trees for wildlife habitat, preservation of a rare species of fern and cost. Each attribute was assigned three different levels (e.g. harvest all, one-half or none of the timber; protect all, one-half or none of the ferns), and three management cost levels for each scenario were defined; $\$ 50, \$ 250$ and $\$ 500$ (see Appendix), giving 243 possible combinations. An orthogonal array was then used to create a succinct subset of all attribute combinations that permits estimation of main effects over the entire range of attribute values. The resulting 18 alternative management programs were then assigned to the questionaires in equal frequency.

Conjoint analysis has been widely used in marketing research and conjoint has recently become increasingly popular in modeling consumer preferences for environmental commodities that have multiple attributes (Dennis, 1998). There are, however, a number of potential problems with this technique.

First, individual responses are made in the context of a hypothetical situation; their actual behavior may be different. Other problems include, but are not limited to: (1) some respondents may not be very familiar with the attributes or activities being valued; (2) results depend in part on the information which is (or is not) provided in the survey; and (3) results may be very sensitive to the format of the questionnaire, attributes or activities excluded, etc. (see Mitchell and Carson, 1989; Hausman, 1993).

Moreover, the activities presented to respondents in this study do not represent many of the complexities associated with actual management decisions. For the sake of simplicity, the notion of co-operation was limited to three adjoining private properties and several simple, tangible activities that could be undertaken (see Appendix). Such assumptions allow us to begin to probe the nature of landowner attitudes towards the concept of cross-boundary co-operation in management activities. Such simple crossboundary co-operation between private landowners is considered to be a necessary core for successfully applying a co-operative management paradigm in a fragmented landscape owned by a non-industrial private individuals and families. If such co-operation will not work in its most elementary sense, then greater co-operation and management activities at a larger scale are certain to fail.

When interpreting the results which follow, these issues should be considered. However, it is also important to note that conjoint analysis can provide information about the probability of landowner participation in management programs that cannot be quantified in any other way.

\section{Study area}

Franklin County, Massachusetts, USA was selected as our study area. Seventy-eight percent of this county is forested, most of which is in private non-industrial ownership. Sixty percent of the parcels in the county contain 50 acres or less. By way of comparison, 59\% of all New England NIPF parcels are 50 acres or smaller and $68 \%$ of all parcels in the US are smaller than 50 acres. Proximity of owner's residence to forestland and land tenure patterns in this county are also very similar to those for the New England region and for the US as a whole. It is important to note that Massachusetts requires all landowners to file 
cutting plans and sites are subject to inspection before, during and after harvests. However, in most other respects this study area is quite typical of much of the Northeastern US.

The conjoint survey was conducted by mail in the fall, 1995; 1250 Franklin County residents owning 10 acres or more were contacted. The survey instrument was designed and pretested using input from focus groups; the Dillman (1978) Total Design Method was used throughout.

\section{Results}

The overall survey response rate was $65 \%$ and the useable response rate was $61.3 \%$, About 49\% of respondents were 35-54 years old, and 74\% had completed at least 1 year of college. The average respondent owned 60 acres of forestland, about 19\% had filed a formal forest management plan, and 54\% had owned their land less than 20 years.

In addition to the conjoint questions, all respondents were asked a series of questions about attitudes toward co-operating with neighbors on land management projects such as habitat improvement, timber harvesting or recreational trail development. Only 18\% agreed with the statement that 'I would not consider co-operating with neighbors on land management projects'. Fifty-six percent said that they would agree to participate in and share the costs of occasional, specific management projects such as building walking trails or arranging for a timber sale with their neighbors. In addition, $28.6 \%$ said they would agree to 'enter into a contractual agreement with neighboring landowners for a fixed period of time (e.g. 5-10 years) to hire one or several professionals to prepare and implement a management plan on all the properties collectively whereby all participating landowners would share equally in the benefits (e.g. timber sale revenues, recreational access, enhanced wildlife habitat) and the expenses (e.g. preparation of the plan, administration of a timber sale, establishment of trails).'

Ratings that respondents assigned to the management scenarios were initially analysed using the traditional conjoint approach. Since the dependent variable in this analysis, rating, takes on discrete integer values, from 1 to 10 , an ordered logit estimating technique was applied to the ratings data [see Equation (1)]. When estimated in this form, the intercept term is decomposed into eight separate dummy variables to account for the intervals between rating levels (McKenzie, 1990). Independent variables are defined in Table 1. Data from both survey types (individual management and co-operative management) were pooled and a dummy variable for survey type, $T=1$ if co-operative version, was included to test for the effect of survey type on ratings, holding all other variables constant. Each individual was asked to rate four scenarios and, as suggested by McKenzie (1993), since respondents tend to center their ratings in different portions of the rating scale, each individual's average rating (Q14RAVG) was included as an independent variable.

Results of this analysis are reported in Table 2. Signs of estimated coefficients were generally consistent with prior expectations. Options that provided more apple tree protection, fern and trail improvements were rated higher. The estimated coefficient for timber harvesting was not statistically different from zero. These findings are consistent with several previous studies which suggest that NIPF owners place higher values on amenities, such as wildlife and recreation, than on timber harvests (Birch, 1996; Brunson et al., 1996).

Ratings declined with cost and preference for non-co-operation (Q15A). Ratings also declined with education and age of owner, a pattern which was not anticipated. However, of particular importance is that the value of the coefficient for survey type, $T$, was negative and statistically significant indicating that ratings given to co-operative alternatives were lower than for individual management alternatives, all else held constant.

The probability that landowners would undertake any of the programs given in the survey was calculated from the second conjoint model shown in Equation (2). The dependent variable in this analysis equals 1 for programs which received a conjoint rating of 10, and 0 otherwise. A logit estimating technique [see Equation (2)] was used with the explanatory variables defined in Table 1. Data from both survey types (individual management and co-operative management) 
Table 1. Explanatory variables used in empirical analysis

\begin{tabular}{|c|c|c|c|}
\hline Variable & Definition & Mean & $\begin{array}{l}\text { Standard } \\
\text { deviation }\end{array}$ \\
\hline Age & Age of owner in years & $53 \cdot 8$ & $12 \cdot 96$ \\
\hline Educ & Education level of owner (1-6) categories & $4 \cdot 01$ & $1 \cdot 50$ \\
\hline Income & Household income level (1-6) categories & $3 \cdot 43$ & $1 \cdot 42$ \\
\hline $\mathrm{T}$ & Survey version Dummy ( 1 if co-op) & 0.50 & $0 \cdot 50$ \\
\hline Apples & Percentage of apple trees maintained $(0,0.5,1)$ & 0.51 & $0 \cdot 40$ \\
\hline Ferns & Percentage of acres of rare ferns saved $(0,0.5,1)$ & 0.50 & $0 \cdot 40$ \\
\hline Trails & Percentage of trail system improved $(0,0.5,1)$ & 0.50 & $0 \cdot 41$ \\
\hline Harvest & Percentage of timberland harvested $(0,0.5,1)$ & 0.47 & $0 \cdot 39$ \\
\hline Cost & Net cost to landowner $(\$ 50, \$ 250, \$ 500)$ & 263 & $0 \cdot 84$ \\
\hline Acres 1 & Acres timberland owned & 60 & 104 \\
\hline Plan & Dummy variable $=1$ if management plan & $0 \cdot 19$ & 0.39 \\
\hline Q15A & $\begin{array}{l}\text { Scale variable for attitude about co-operation (1-5) } \\
\text { with } 5 \text { indicating landowner is strongly opposed } \\
\text { to co-operation }\end{array}$ & $2 \cdot 40$ & $1 \cdot 26$ \\
\hline Q14RAVG & Average rating, each individual & $3 \cdot 33$ & $1 \cdot 77$ \\
\hline
\end{tabular}

Table 2. Traditional conjoint model results: pooled ratings model

\begin{tabular}{lcc}
\hline Variable & $\begin{array}{c}\text { Estimated } \\
\text { coefficient }\end{array}$ & $T$ value \\
\hline$T$ & $-0 \cdot 139$ & $1 \cdot 61^{*}$ \\
Q14RAVG & $0 \cdot 759$ & $24 \cdot 47^{* *}$ \\
Apples & $0 \cdot 895$ & $8 \cdot 27^{* *}$ \\
Ferns & $0 \cdot 916$ & $8 \cdot 41^{* *}$ \\
Trails & $0 \cdot 295$ & $2 \cdot 82^{* *}$ \\
Harvest & $0 \cdot 136$ & $1 \cdot 25$ \\
Cost & $-0 \cdot 0016$ & $6 \cdot 80^{* *}$ \\
Age & $-0 \cdot 017$ & $5 \cdot 77^{* *}$ \\
Educ & $-0 \cdot 071$ & $2.31^{* *}$ \\
Income & $-0 \cdot 047$ & $1 \cdot 42$ \\
Acres 1 & $-0 \cdot 0007$ & $1 \cdot 49$ \\
Plan & $-0 \cdot 024$ & $0 \cdot 99$ \\
Q15A & $-0 \cdot 064$ & $2 \cdot 40^{* *}$ \\
MU (1) & $0 \cdot 889$ & $16 \cdot 33^{* *}$ \\
MU (2) & $1 \cdot 495$ & $22 \cdot 64^{* *}$ \\
MU (3) & $1 \cdot 857$ & $25 \cdot 95^{* *}$ \\
MU (4) & $2 \cdot 781$ & $32 \cdot 85^{* *}$ \\
MU (5) & 3.091 & $34 \cdot 69^{* *}$ \\
MU (6) & 3.551 & $37 \cdot 28^{* *}$ \\
MU (7) & $4 \cdot 271$ & $39 \cdot 03^{* *}$ \\
MU (8) & 4.948 & $40 \cdot 36^{* *}$ \\
\hline
\end{tabular}

Chi-square $=1074 * * . N=1832 . *$ Significant at $10 \%$ level. ** Significant at $5 \%$ level. ${ }^{a}=$ Absolute value.

were pooled and a dummy variable for survey type, $T=1$ if co-operative version, was included to test for the effect of co-operative management on the probability of program adoption.
Table 3. Logit conjoint model results

\begin{tabular}{lcc}
\hline Variable & $\begin{array}{c}\text { Estimated } \\
\text { coefficient }\end{array}$ & $\begin{array}{c}\text { Chi-square } \\
P \text { value }\end{array}$ \\
\hline Intercept & $-3.61^{* *}$ & 0.0001 \\
$T$ & -0.24 & 0.19 \\
Apples & $1.36^{* *}$ & 0.0001 \\
Ferns & $1.11^{* *}$ & 0.0001 \\
Trails & $0.49^{*}$ & 0.06 \\
Harvest & 0.17 & 0.51 \\
Cost & $-0.00107^{* *}$ & 0.04 \\
Age & -0.007 & 0.37 \\
Educ & -0.046 & 0.50 \\
Income & $0.124^{*}$ & 0.07 \\
Acres 1 & -0.0009 & 0.42 \\
Plan & -0.066 & 0.79 \\
Q15A & $-0.199^{* *}$ & 0.02 \\
\hline
\end{tabular}

Chi-square $=85 \cdot 71 * * . \quad N=1681$. Significant at $10 \%$ level. ${ }^{* *}$ Significant at $5 \%$ level.

Results of this analysis are reported in Table 3. Probability of program adoption increased in the apple tree, fern and trail attributes. Again, the effect of timber harvest was not statistically different from zero. The probability of program acceptance increased with income and declined with cost, and preference for non-co-operation (Q15A). The likelihood of participation was not statistically related to landowner education, age or parcel size. The value of the coefficient for survey type, $T$, was negative but not statistically significant indicating that the probability of definitely adopting co-operative alternatives 
Table 4. Calculated probability of program adoption

\begin{tabular}{lc}
\hline Program $^{a}$ & $\begin{array}{c}\text { Probability of } \\
\text { adoption }\end{array}$ \\
\hline 1. Cost $=\$ 50$, all apple trees maintained & 0.098 \\
2. Average Cost $(\$ 263)$, all apple trees maintained & 0.079 \\
3. Average Cost $(\$ 263)$, no apple trees maintained & 0.022 \\
4. $\$ 50$ cost, all apple trees maintained and all ferns & 0.182 \\
$\quad$ saved, no timber harvest, 30-year-old owner & \\
\hline
\end{tabular}

${ }^{a}$ All independent variables not indicated are set at their mean value (see Table 1).

was not different than for identical individual management alternatives, all else held constant. Sensitivity to model specification was investigated by repeating this analysis with the dependent variable equaling 1 for programs which received a conjoint rating greater than or equal to 7 , and 0 otherwise. Signs and magnitudes of key coefficients, such as apples, ferns, cost and harvests were very similar to those reported in Table 3.

The probability that several different management programs would be undertaken by respondents is presented in Table 4 . In interpreting these results, it is important to note that only about $10 \%$ of respondents said they would definitely undertake one of the management programs presented in the conjoint survey (i.e. assigned a rating of 10). Since many others indicated that they might adopt a program (i.e. assigned a rating of less than 10 but greater than 1 ), the probabilities presented in Table 4 should be viewed as conservative estimates. And, all variables not indicated in Table 4 are set at their mean value (see Table 1).

With respect to the programs presented in Table 4, in all cases the likelihood that a program would definitely by undertaken is not affected by whether co-operative management is involved. As expected, an increase in management cost reduces the likelihood that management programs would be undertaken and if fewer positive attributes are involved (no maintenance of apple trees, for example) the probability that a program would definitely be undertaken is very small.

Referring to Tables 3 and 4, low cost management programs which focus on non-timber outputs such as maintenance of apple trees and protection of ferns have the highest likelihood of adoption (see program 4, Table 4).

\section{Applications and conclusion}

Co-operative management between landowners is one potential solution to the problems posed by forest fragmentation. Although landowners rated co-operative management programs slightly below independently managed ones our results indicate that they were not less likely to definitely undertake programs involving co-operation. The estimated probability of program adoption was primarily determined by other factors such as whether management programs focus on wildlife habitat enhancement (e.g. apple tree maintenance) and non-game aspects of the land (e.g. protection of rare ferns). Timber harvest was not a statistically significant factor influencing either ratings or the likelihood of program adoption. Moreover, program ratings and the probability of program adoption were not statistically related to the number of acres owned, or whether a management plan had been prepared. This suggests that educational programs or management incentives should target a broad spectrum of landowners while focusing on amenities, such as wildlife habitat, rather than timber harvests.

Low cost management programs offering significant enhancements in non-timber benefits (apples, ferns and trails) were estimated to have a small likelihood of adoption. However, it is important to note that the logit model provides a conservative estimate of program adoption. Moreover, actual management programs, such as the Massachusetts Forest Stewardship program, have similar adoption rates. And, even though adoption rates are small, a substantial amount of acreage is involved. The 
adoption rates estimated in this study could therefore enhance non-timber benefits provided by NIPFs, but further research is needed to identify the types of programs that might have a more substantial impact on landowner co-operation and program adoption.

Results of this study are likely to be relevant for areas that are similar in geographic, socio-economic, and ecological contexts, i.e. forested landscapes dominated by a multitude of small NIPF landowners. These results may be less relevant in areas where timber income is a more important factor. An overall implication, however, is that it is important to understand owner attitudes and the programs they are willing to undertake when designing or refining public policy for privately owned forestland.

\section{References}

Birch, T. W. (1996). Private Forest-Land Owners Of The United States, 1994. Resource Bulletin NE-134. Radnor, PA: USDA Forest Service, Northeastern Research Station.

Boxall, P., Adamowicz, W., Swait, J., Williams, M. and Larviere, J. (1996). A comparison of stated preference methods for environmental valuation. Ecological Economics 18, 243-253.

Brunson, M.W., Yarrow, D., Roberts, S., Guynn, D. and Kuhns, M. (1996). Nonindustrial private forest owners and ecosystem management. Journal of Forestry June, 14-21.

Dennis, D.F. (1998). Analyzing public inputs to multiple objective decisions on national forests using conjoint analysis. Forest Science 44, 421429.

Dillman, D. (1978). Mail and Telephone Surveys: The Total Design Method. New York: John Wiley and Sons.

Hausman, J. (Ed.) (1993). Contingent Valuation: A Critical Assessment. New York: North-Holland.

Kuusela, K. (1994). Forest Resources in Europe 1950-1990. European Forest Institute Research Report 1, Cambridge University Press.

Marghesscu, T. (1997). Forestry extension in countries of central and eastern Europe. In $A p$ proaches to Extension in Forestry-experiences and Future Developments. Proceedings, IUFRO. (R. Beck, ed.), pp. 83-91. 9/30-10/4/96. Freising, Germany.

McKenzie, J. (1990). Conjoint analysis of deer hunting. Northeastern Journal of Agricultural and Research Economics 19, 109-117.

McKenzie, J. (1993). A comparison of contingent preference models. American Journal of Agricultural Economics 75, 593-603.
Mitchell, R. and Carson, R. (1989). Using Surveys To Value Public Goods. The Contingent Valuation Method. Washington, DC: Resources For The Future.

Rickenbach, M.G., Kittredge, D., Dennis, D. and Stevens, T. (1998). Ecosystem management: capturing the concept for woodland owners. Journal of Forestry 96, 18-24.

Roe, K., Boyle, K. Swait, and Teisl, M. (1996). Using conjoint analysis to derive estimates of compensating variation. Journal of Environmental Economics and Management 31, 145-159.

USDA Forest Service (1995). The Forest Service Program For Forest and Rangeland Resources: A Long-Term Strategic Plan. Draft 1995 RPA Program. Washington, DC: USDA Forest Service.

USDA Forest Service (1988). An Analysis Of The Timber Situation In The United States: 19892040. Washington, DC: USDA Forest Service.

\section{Appendix 1}

\section{Individual management version}

Please consider the hypothetical situation in which you own the forestland shown in Figure 1. Four management options are presented on the next page, each of which is a set of activities that can be implemented on your land in Franklin County, Massachusetts. Each arrangement has a net cost based on possible income from the sale of timber and expenses associated with other management activities. Please consider and compare the arrangements presented and indicate how you would rate each on a scale of 1-10. Please use 10 for arrangements, if any, that you would definitely undertake. Use 1 for arrangements, if any, that you would definitely not undertake. If you are not sure, use 2 through 9 to indicate how likely you would be to undertake each option.

\section{Option A}

- Maintain of the apple trees shown on Figure 1 which benefit wildlife.

- Protect of the acres containing a rare species of fern shown in Figure 1 by not harvesting timber in this area or otherwise disturbing the ferns. 
- Improve of the trail network shown in Figure 1. Improvements, if any, would include the cost of building a footbridge over the stream and clearing scenic vistas.

- Harvest timber from of the lands shown on Figure 1. Any harvest would be selective, designed to remove poorly formed and leave some high quality trees; 25-30\% of all trees would be removed.

- This option would have a net cost to you of $\$$

RATING (1-10): ......

\section{Option B}

- Maintain of the apple trees shown on Figure 1 which benefit wildlife.

- Protect of the acres containing a rare species of fern shown in Figure 1 by not harvesting timber in this area or otherwise disturbing the ferns.

- Improve of the trail network shown in Figure 1. Improvements, if any, would include the cost of building a footbridge over the stream and clearing scenic vistas.

- Harvest timber from of the lands shown on Figure 1. Any harvest would be selective, designed to remove poorly formed and leave some high quality trees; 25-30\% of all trees would be removed.

- This option would have a net cost to you of $\$$

RATING (1-10): .....

\section{Option C}

- Maintain of the apple trees shown on Figure 1 which benefit wildlife.

- Protect of the acres containing a rare species of fern shown in Figure 1 by not harvesting timber in this area or otherwise disturbing the ferns.

- Improve of the trail network shown in Figure 1. Improvements, if any, would include the cost of building a footbridge over the stream and clearing scenic vistas.

- Harvest timber from of the lands shown on Figure 1. Any harvest would be selective, designed to remove poorly formed and leave some high quality trees; 25-30\% of all trees would be removed.
- This option would have a net cost to you of $\$$

RATING (1-10): ......

\section{Option D}

- Maintain of the apple trees shown on Figure 1 which benefit wildlife.

- Protect of the acres containing a rare species of fern shown in Figure 1 by not harvesting timber in this area or otherwise disturbing the ferns.

- Improve of the trail network shown in Figure 1. Improvements, if any, would include the cost of building a footbridge over the stream and clearing scenic vistas.

- Harvest timber from of the lands shown on Figure 1. Any harvest would be selective, designed to remove poorly formed and leave some high quality trees; $25-30 \%$ of all trees would be removed.

- This option would have a net cost to you of $\$$

RATING (1-10): ......

\section{Co-operative management version}

Please consider the hypothetical situation shown in Figure 1a in which your forestland is adjacent to two other parcels. Suppose you own property number 1 and that you are asked to consider co-operating with your neighbors for the purpose of managing your forestland as part of a larger unit. Four cooperative arrangements are presented on the next two pages, each of which is a set of activities that can be implemented on forestland in Franklin County, Massachusetts. Each arrangement has a net cost based on possible income from the sale of timber and expenses associated with other management activities. Please consider and compare the co-operative arrangements presented and indicate how you would rate each on a scale of 1-10. Please use 10 for arrangements, if any, that you would definitely undertake. Use 1 for arrangements, if any, that you would definitely not undertake. If you are not sure, 
use 2 through 9 to indicate how likely you would be to enter into each arrangement.

\section{Arrangement A}

- Agree to maintain of the apple trees shown on Figure 1a which benefit wildlife. Maintenance cost, if any would be shared equally with your neighbors.

- Agree to protect of the acres containing a rare species of fern shown in Figure 1a by not harvesting timber in this area or otherwise disturbing the ferns.

- Agree to improve of the trail network shown in Figure 1a. The cost of improvements, if any, would be shared equally and would include the cost of building a footbridge over the stream and clearing scenic vistas.

- Agree to harvest timber from of the lands shown on Figure 1a. Costs and revenues, if any, would be disturbed to each landowner in proportion to a professional forester's estimate of value coming from each parcel. Any harvest would be selective, designed to remove poorly formed trees and leave some of the high quality; $25-30 \%$ of all trees would be removed.

- This option would have a net cost to you of $\$$

RATING (1-10): .....

\section{Arrangement B}

- Agree to maintain of the apple trees shown on Figure 1a which benefit wildlife. Maintenance cost, if any would be shared equally with your neighbors.

- Agree to protect of the acres containing a rare species of fern shown in Figure 1a by not harvesting timber in this area or otherwise disturbing the ferns.

- Agree to improve of the trail network shown in Figure 1a. The cost of improvements, if any, would be shared equally and would include the cost of building a footbridge over the stream and clearing scenic vistas.

- Agree to harvest timber from of the lands shown on Figure 1a. Costs and revenues, if any, would be disturbed to each landowner in proportion to a professional forester's estimate of value coming from each parcel. Any harvest would be selective, designed to remove poorly formed trees and leave some of high quality; 25$30 \%$ of all trees would be removed.

- This option would have a net cost to you of $\$$

RATING (1-10): .....

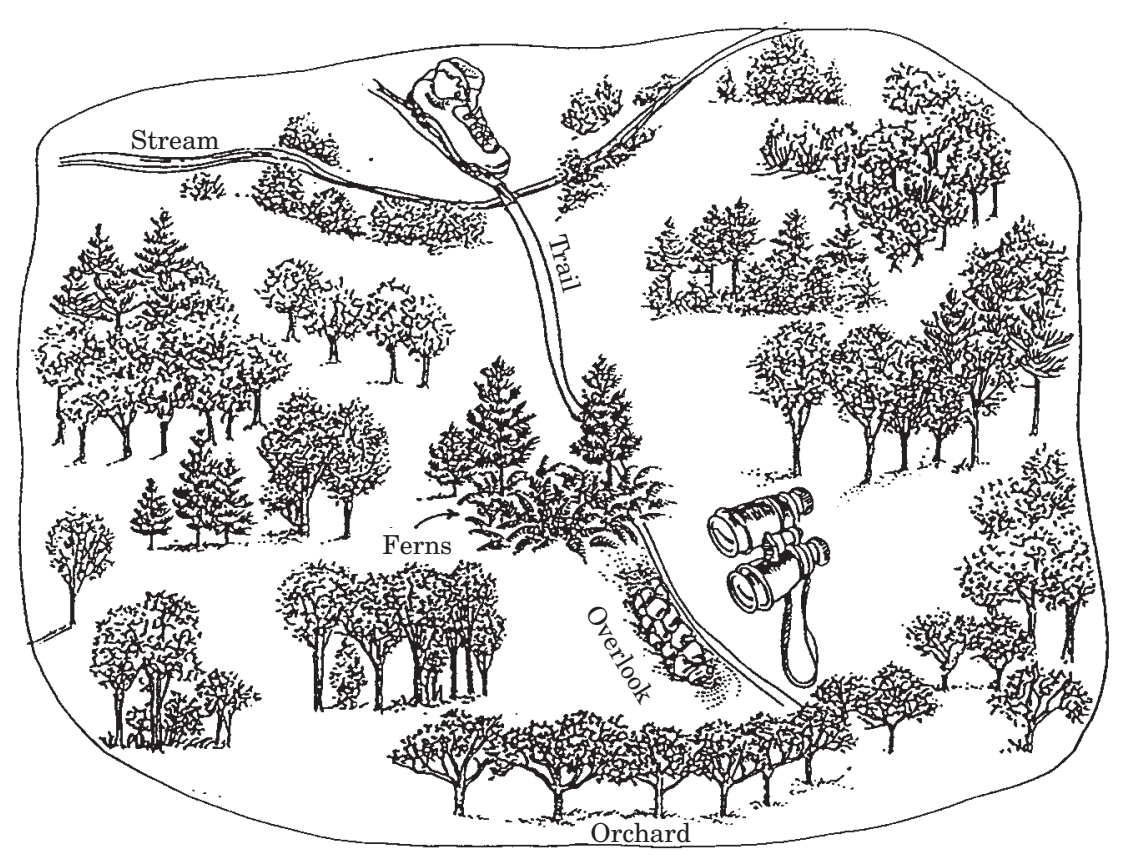

Figure 1 


\section{Arrangement C}

- Agree to maintain of the apple trees shown on Figure 1a which benefit wildlife. Maintenance cost, if any would be shared equally with your neighbors.

- Agree to protect of the acres containing a rare species of fern shown in Figure 1a by not harvesting timber in this area or otherwise disturbing the ferns.

- Agree to improve of the trail network shown in Figure 1a. The cost of improvements, if any, would be shared equally and would include the cost of building a footbridge over the stream and clearing scenic vistas.

- Agree to harvest timber from of the lands shown in Figure 1a. Costs and revenues, if any, would be distributed to each landowner in proportion to a professional forester's estimate of value coming from each parcel. Any harvest would be selective, designed to remove poorly formed trees and leave some of high quality; 25$30 \%$ of all trees would be removed.

- This option would have a net cost to you of $\$$

RATING (1-10): ......

\section{Arrangement $D$}

- Agree to maintain of the apple trees shown on Figure 1a which benefit wildlife. Maintenance cost, if any would be shared equally with your neighbors.

- Agree to protect of the acres containing a rare species of fern shown in Figure $1 \mathrm{a}$ by not harvesting timber in this area or otherwise disturbing the ferns.

- Agree to improve of the trail network shown in Figure 1a. The cost of improvements, if any, would be shared equally and would include the cost of building a footbridge over the stream and clearing scenic vistas.

- Agree to harvest timber from of the lands shown on Figure 1a. Costs and revenues, if any, would be distributed to each landowner in proportion to a professional forester's estimate of value coming from each parcel. Any harvest would be selective, designed to remove poorly formed trees and leave some of high quality; 25$30 \%$ of all trees would be removed.

- This option would have a net cost to you of $\$$

RATING (1-10): ......

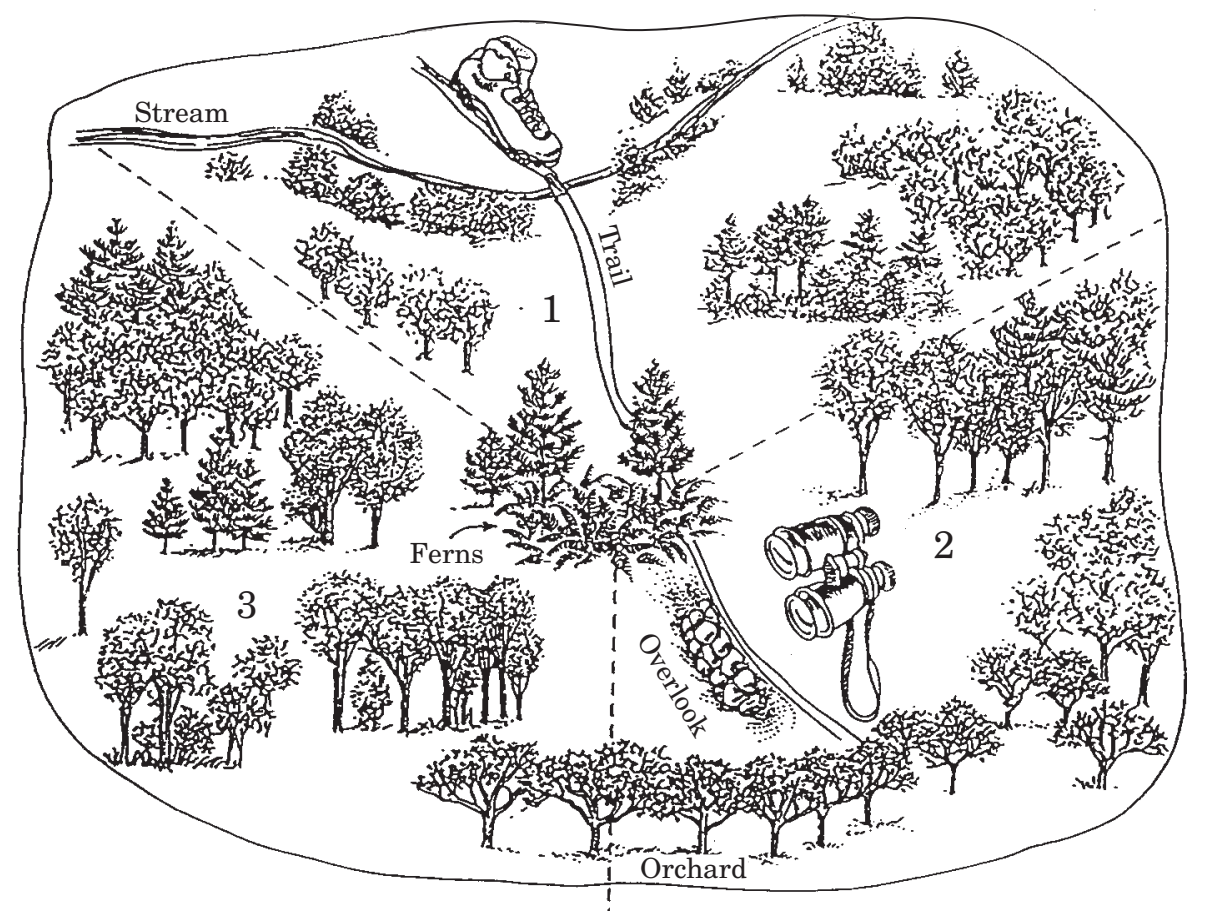

Figure 1a 